\title{
A phase Ib study of everolimus combined with metformin for patients with advanced cancer
}

\author{
Remco J. Molenaar ${ }^{1,2,3}$ - Tim van de Venne ${ }^{1,2,3}$ - Mariëtte J. Weterman ${ }^{1,3}$. \\ Ron A. Mathot $^{4}$ • Heinz-Josef Klümpen ${ }^{1,3}$ • Dick J. Richel ${ }^{1,3}$ • Johanna W. Wilmink ${ }^{1,3}$
}

Received: 8 May 2017 / Accepted: 30 May 2017 /Published online: 15 June 2017

(C) The Author(s) 2017. This article is an open access publication

\begin{abstract}
Summary Background The efficacy to monotherapy with the mTOR inhibitor everolimus in advanced cancer is often limited due to therapy resistance. Combining everolimus with metformin may decrease the chance of therapy resistance. Methods Patients received everolimus and metformin in a $3+3$ dose-escalation scheme. Objectives were to determine the dose-limiting toxicities (DLTs), maximum tolerated dose, toxic effects, pharmacokinetics and anti-tumour efficacy. Results 9 patients received study treatment for a median duration of 48 days (range: 4-78). 6 patients discontinued due to toxicity and 3 patients because of progressive disease. At the starting dose level of $10 \mathrm{mg}$ everolimus qd and $500 \mathrm{mg}$ metformin bid, 3 out of 5 patients experienced a DLT. After deescalation to $5 \mathrm{mg}$ everolimus qd and $500 \mathrm{mg}$ metformin bid, considerable toxicity was still observed and patient enrollment was terminated. In pharmacokinetic analyses, metformin was
\end{abstract}

Electronic supplementary material The online version of this article (doi:10.1007/s10637-017-0478-4) contains supplementary material, which is available to authorized users.

Johanna W. Wilmink

j.w.wilmink@amc.nl

1 Department of Medical Oncology, Division of Internal Medicine, Academic Medical Center, University of Amsterdam, Meibergdreef 15, 1105, AZ Amsterdam, The Netherlands

2 Department of Medical Biology, Academic Medical Center, University of Amsterdam, Meibergdreef 15, 1105, AZ Amsterdam, The Netherlands

3 Cancer Center Amsterdam, Location Academic Medical Center, University of Amsterdam, Meibergdreef 15, 1105, AZ Amsterdam, The Netherlands

4 Department of Clinical Pharmacology, Academic Medical Center, University of Amsterdam, Meibergdreef 15, 1105, AZ Amsterdam, The Netherlands eliminated slower when co-administered with everolimus than as single-agent. After 9 weeks of treatment, 3 patients were still on study and all had stable disease. Conclusion The combination of everolimus and metformin is poorly tolerated in patients with advanced cancer. The pharmacokinetic interaction between everolimus and metformin may have implications for diabetic cancer patients that are treated with these drugs. Our results advocate for future clinical trials with combinations of other mTOR inhibitors and biguanides.

Keywords Everolimus · Metformin · Cancer . Pharmacokinetics $\cdot$ Safety $\cdot$ Toxicity

\section{Introduction}

Many cancers display activation of the phosphatidylinositol 3kinase (PI3K)/protein kinase B (AKT)/mammalian target of rapamycin (mTOR) pathway, which plays an important role in controlling the proliferation and metabolism of cancer cells [1]. However, only few malignancies demonstrate clinical response to mTOR inhibitors, such as everolimus. Accordingly, mTOR inhibitors are only FDA- and EMA-approved for use in patients with a few types of cancer, such as mantle cell lymphoma, pancreatic neuroendocrine tumors, advanced renal cell carcinoma, and giant cell astrocytoma [2-6].

In other solid organ malignancies, mTOR inhibitors show clinical responses, though in most cases not enough to warrant monotherapy and with considerable toxicity. A major issue is that most cancers develop resistance against monotherapy with mTOR inhibitors. One of the proposed mechanisms how tumor cells develop resistance to mTOR inhibition is through the mTOR-dependent negative feedback loop that acts to inhibit PI3K/AKT activity. Via this mechanism, drugs that target mTOR inhibit neoplastic processes downstream of mTOR but 
also the feedback loop. Subsequently, this may activate AKT [7] and its downstream oncogenic effects [8], thereby limiting the efficacy of monotherapy with mTOR inhibitors $[9,10]$.

A possible way to prevent the development of therapy resistance against mTOR inhibitors is by combining these drugs with the mitochondrial respiration inhibitor metformin, a drug commonly prescribed for the treatment of type 2 diabetes mellitus (T2DM). Several in vitro studies that combined metformin with cytotoxic agents or with everolimus have shown a synergistic inhibition of breast cancer cell growth, compared to single-agent therapy $[11,12]$. Metformin's synergistic antiproliferative effect in combination with everolimus is a result of activation of $5^{\prime}$ adenosine monophosphate-activated protein kinase (AMPK), which inhibits AKT. Via this mechanism, metformin counteracts the oncogenic AKT activation that is induced by mTOR inhibition [13, 14]. In short, because metformin may delay or overcome the mechanism of treatment resistance against monotherapy with an mTOR inhibitor, there is a rationale for combining these two drugs [7]. In a retrospective combined analysis of 94 patients from three clinical trials with various mTOR inhibitors for the treatment of endometrial cancer, self-reported metformin use was associated with a higher response rate to an mTOR inhibitor (18 vs. $7 \%$ ) and a lower rate of disease progression (12 vs. 33\%) [15]. Also, a clinical trial combining everolimus and letrozole for the treatment of endometrial cancer found that patients that received metformin to treat hyperglycemia (either in the context of pre-existing diabetes or study treatment-related) had a significantly higher response rate (56 vs. 23\%) [16]. Moreover, metformin has attracted interest as an anti-cancer drug [17] since an association between metformin use in T2DM patients and a reduced risk of breast, colon, pancreas and prostate cancer was acknowledged [18-23], as well as a reduced risk of mortality, as compared with patients treated with insulin or sulfonylureas [24].

The present clinical trial investigates the safety and maximum tolerated dose (MTD) of a combination therapy with everolimus and metformin in patients with advanced cancer. As secondary objectives, the pharmacokinetics of everolimus and metformin combination treatment and tumor responses to study treatment were assessed.

\section{Materials and methods}

Patient population Eligible patients were aged $\geq 18$ years with histological or cytological confirmed solid malignancies that were refractory to standard therapies, or for which no standard treatment option was available. Other eligibility criteria included WHO performance status $\leq 2$, estimated life expectancy of $\geq 3$ months, adequate bone marrow (white blood cell count $\geq 3.0 \times 10^{9} / 1$, platelets $\geq 100 \times 10^{9} / 1$ ), hepatic (serum bilirubin $\leq 1.5 \times$ upper limit of normal (ULN),
ALAT/ASAT $\leq 2.5 \times$ ULN or in case of liver metastases $\leq 5 \times \mathrm{ULN}$ ) and renal function (serum creatinine $\leq 150 \mu \mathrm{mol} /$ 1). Patients also had to be mentally, physically and geographically able to undergo the study treatment and follow-up. Patients were ineligible if they were known with a serious concomitant medical condition, such as unstable angina pectoris, symptomatic congestive heart failure, myocardial infarction within the last 6 months before screening, serious uncontrolled cardiac arrhythmia, uncontrolled diabetes (fasting serum glucose $>2 \times$ ULN), severe infection, cirrhosis, chronic active/persistent hepatitis or severly impaired lung function. Furthermore, patients were ineligible when they had a known hypersensitivity to either study drug, if they had used either study drug in the previous 6 months or when they were concomitantly treated with strong CYP3A4/3A5/2C8 inhibitors/ inducers. Women were ineligible when they were pregnant or lactating. All patients gave written informed consent.

Medical ethics The study protocol was approved by the Medical Ethics Committee of the Academic Medical Center (reference number NL_37906.018.12) and was conducted in accordance with the Declaration of Helsinki and Good Clinical Practice guidelines.

Study design This was a phase I, open-label, single-center, dose escalation study to assess the safety, DLTs, maximum tolerated dose (MTD) and the pharmacokinetic interaction of the combination of everolimus and metformin. The study was conducted at the Academic Medical Center (The Netherlands). At least three patients per dose level were recruited and the cohort at this dose level was to be expanded to six patients if $1 / 3$ patients experienced a DLT. Dose escalation to the next dose level was to be permitted if no DLT occurred in $0 / 3$ or in $\leq 1 / 6$ patients. In case of DLT(s) in $\geq 1 / 3$ or in $\geq 2 / 6$ patients, that dose level was to be declared intolerable and doseescalation occurred. If dose level -1 was also intolerable, the study was to be terminated without establishment of an MTD. A DLT was defined as any of the following events related to study treatment and occurring during the first treatment cycle, defined by National Cancer Institute Common Terminology Criteria for Adverse Events version 3.0 (CTCAE): neutropenia grade 4 lasting $>5$ days or febrile neutropenia grade 3 (fever $\geq 38.5^{\circ} \mathrm{C}$ ), grade $\geq 3$ anemia, grade $\geq 4$ trombocytopenia or grade 3 trombocytopenia with bleeding, vomiting grade $\geq 2$, diarrhoea grade $\geq 2$ or any other toxicity grade $\geq 3$ (excluding alopecia), despite optimal supportive care. In case of measurable disease, tumor measurements were performed using a CT scan at baseline and every nine weeks and were evaluated in accordance with the Response Evaluation Criteria in Solid Tumors (RECIST 1.1) [25].

Study treatment During the first seven days of treatment, patients were treated with single-agent everolimus to reach 
steady-state concentrations. Treatment with metformin bid started on day 8 . The everolimus and metformin doses were to be de-escalated or escalated as shown in Table 1. Metformin was administered bid instead of qd at dose level 1 to mimic conventional metformin dosing schedules in T2DM and because of the short elimination half-life $\left(\mathrm{t}_{1 / 2}\right)$ of metformin (5 h) [26]. In dose level-1, the everolimus dose was decreased rather than the metformin dose or the metformin dosing frequency because metformin pills $<500 \mathrm{mg}$ were not available and because of the difference in $t_{1 / 2}$ between metformin $(5 \mathrm{~h})$ and everolimus $(30 \mathrm{~h})[26,27]$. In the event of intolerable toxicity at dose level 1 , the exposure to the study treatment is probably decreased more effectively by decreasing the everolimus dose than the metformin dose or its dosing frequency.

Pharmacokinetic analysis To determine the pharmacokinetic interaction between everolimus and metformin, patients received (only for pharmacokinetic purposes) one single morning administration of metformin 1 day prior to start of treatment (day -1$)$, at the dose level that the patient would receive at start of treatment. Blood samples were drawn on $t=0$ (predose), 1, 2, 4, 6, 8 and $12 \mathrm{~h}$ after the morning doses of metformin on day -1 and 15 . Blood samples for everolimus were drawn on day 7 (without metformin) and on day 15 (with metformin), both at predose and at 1, 2, 4, 6, 8, 12 and $24 \mathrm{~h}$ after administration of everolimus. Using these blood samples, full pharmacokinetic $12 / 24$-h profiles of the metformin and everolimus plasma concentrations were determined, both as single agents and in combination with each other. Everolimus was determined in whole blood and metformin was determined in serum using high-performance liquid chromatography with tandem mass spectrometry (HPLC-MS/ MS). According to conventional pharmacokinetic principles [28], the area under the curve (AUC) of the serum concentration curves was calculated as the AUC from $t=0$ to infinity for the first administration of a study drug, i.e., single-agent drug administration at day -1 for metformin, and as the AUC from $t=0$ to $t_{\text {last }}$ for steady-state drug administration, i.e., at days 7 and 15 for everolimus (as single-agent and in combination

Table 1 Dose-escalation schedule for everolimus and metformin. Metformin is given twice daily (the daily dose is double the shown dose)

\begin{tabular}{lll}
\hline Dose level & Everolimus (mg) & Metformin (mg, bid) \\
\hline-1 & 5 & 500 \\
1 & 10 & 500 \\
$2^{*}$ & 10 & 850 \\
$3^{*}$ & 10 & 1000 \\
$4^{*}$ & 10 & 1350 \\
$5^{*}$ & 10 & 1500 \\
$6^{*}$ & 10 & 1850 \\
\hline
\end{tabular}

* Not reached in this dose-escalation study with metformin, respectively) and at day 15 for metformin when it was combined with everolimus. $\mathrm{T}_{\text {last }}$ was the time point directly preceding the next dose for that agent, i.e., $12 \mathrm{~h}$ for metformin bid and $24 \mathrm{~h}$ for everolimus qd.

Evaluation of radiological tumor responses Tumor responses were calculated as the relative difference between the volume of the target lesions at the radiological assessment during study inclusion and the radiological assessment that showed the best overall response. The cut-off marks of the total sum of the volume of the target lesions for progressive disease, stable disease and partial response were $+20 \%$ and $-30 \%$, respectively. Complete response was defined as a disappearance of all target lesions.

Statistical analysis Descriptive statistics were used for evaluation of the adverse events, safety and efficacy of everolimus and metformin. The pharmacokinetic parameters were calculated using PKSolver [29]. All $P$ values were calculated using the $\mathrm{R}$ statistical programming language (paired Student's $t$-test).

\section{Results}

Characterization of the study cohort In total, 12 patients were screened for eligibility between January 2013 and February 2014. Three patients did not meet the study inclusion criteria; one because of inadequate renal function, one because of inadequate bone marrow function, and one because of dysphagia. Table 2 summarizes the baseline characteristics of the nine eligible patients that were enrolled in the study. All patients had received one or more lines of treatment prior to study enrolment. Six patients received at least four weeks of study treatment and were thus evaluable for toxicity assessments (Table 3). Patients stayed on the study for a median duration of 48 days (range: 4-78). Two patients temporarily interrupted treatment: in one case due to trombocytopenia and in one case due to skin rash. Following treatment interruption, these patients received a $50 \%$ dose reduction of everolimus and metformin, respectively.

MTD and DLTs Nine patients started the study regimen consisting of one week of everolimus followed by the addition of metformin. Of the eight evaluable patients that received everolimus and metformin, five patients discontinued their study participation due to toxicity reasons and three patients because of progressive disease. Of the three patients who entered the study at the starting dose level of $10 \mathrm{mg}$ everolimus qd and $500 \mathrm{mg}$ metformin bid, one experienced a DLT (thrombocytopenia). The cohort receiving dose level 1 was then expanded, where after two more patients experienced a DLT (one case of thrombocytopenia and one case of skin rash). According to the protocol, the dose level was de-escalated to 
Table 2 Patient demographics and disease characteristics. Chemotherapy regimens were given in an advanced setting unless stated otherwise

\begin{tabular}{|c|c|c|c|c|c|c|c|c|}
\hline Pt \# & Gender & Age & WHO-PS & $\begin{array}{l}\text { Primary } \\
\text { diagnosis }\end{array}$ & $\begin{array}{l}\text { Earlier } \\
\text { surgery }\end{array}$ & $\begin{array}{l}\text { Earlier } \\
\text { chemotherapy }\end{array}$ & $\begin{array}{l}\text { Earlier } \\
\text { radiotherapy }\end{array}$ & $\begin{array}{l}\text { Time since } \\
\text { initial diagnosis } \\
\text { (in years) }\end{array}$ \\
\hline 1 & Male & 68 & 1 & Colorectal cancer & $\begin{array}{l}\text { Yes, colostomy } \\
\text { (palliative) }\end{array}$ & $\begin{array}{l}\text { Irinotecan, capecitabine } \\
\text { oxaliplatin, bevacizumab }\end{array}$ & No & 1.28 \\
\hline 2 & Male & 69 & 1 & Colon cancer & $\begin{array}{l}\text { Yes, hemicolectomy } \\
\text { right side (curative) }\end{array}$ & $\begin{array}{l}\text { Capecitabine } \\
\text { (1 neoadjuvant } \\
\text { course, } 2 \text { courses } \\
\text { or advanced disease })\end{array}$ & No & 3.51 \\
\hline 3 & Male & 57 & 1 & Pancreatic cancer & No & Gemcitabine & Yes, advanced & 0.92 \\
\hline 4 & Male & 62 & 0 & Pancreatic cancer & Yes, gastrojejunostomy (palliative) & $\begin{array}{l}\text { Gemcitabine, erlotinib, } \\
\text { FOLFIRINOX }\end{array}$ & No & 2.38 \\
\hline 5 & Female & 58 & - & Vulvar cancer & $\begin{array}{l}\text { Yes, vulvectomy } \\
\text { with lymphadenectomy } \\
\text { (curative) }\end{array}$ & Capecitabine & Yes, adjuvant & 1.07 \\
\hline 6 & Female & 51 & 1 & Cervical cancer & $\begin{array}{l}\text { Yes, lymph nodes } \\
\text { debulking (curative) }\end{array}$ & $\begin{array}{l}\text { Cisplatin (1 neoadjuvant } \\
\text { course, } 1 \text { course } \\
\text { for advanced disease), } \\
\text { paclitaxel }\end{array}$ & Yes, adjuvant & 1.82 \\
\hline 7 & Male & 58 & 0 & Gastric cancer & $\begin{array}{l}\text { Yes, total gastric } \\
\text { resection } \\
\text { withesophago-jejunostomy } \\
\text { and spleen extirpation (curative) }\end{array}$ & $\begin{array}{l}\text { Erubiline, capecitabine, } \\
\quad \text { cisplatin (1 neoadjuvant } \\
\quad \text { course, } 1 \text { adjuvant course) } \\
\text { Capecitabine, } \\
\text { oxaliplatin, } \\
\text { irinotecan }\end{array}$ & Yes, adjuvant & 3.12 \\
\hline 8 & Male & 55 & 1 & Pancreatic cancer & No & FOLFIRINOX & No & 1.05 \\
\hline 9 & Male & 63 & 1 & Cholangiocarcinoma & No & Gemcitabine, cisplatin & No & 1.41 \\
\hline
\end{tabular}

Abbreviations: $p t$ patient, WHO-PS World Health Organisation performance status

$5 \mathrm{mg}$ everolimus qd and $500 \mathrm{mg}$ metformin bid, at which no more DLTs were observed, but the toxicity of study treatment persisted (Tables 3 and 4). Subsequently, patient enrollment in the study was terminated. Regarding SAEs, one patient had to be hospitalized for a sepsis, one patient had to undergo surgery for a bile duct stenosis and obstructed esophagus (PTC drain and stent biliary duct, neo-gastric tube and stent) and one patient had to undergo an intervention for cholangitis and a liver abscess (PTC drain revised and abscess drainage).

Safety The treatment-related CTC-graded adverse events per dose level are listed in Table 4. Regarding severe (grade 3/4)

Table 3 Description of administered doses, dose-limiting toxicities and serious adverse events. Patient \#9 discontinued study treatment after 4 days on study due to toxicity. This is not shown in the table because the observed toxicity was due to everolimus monotherapy, not the study treatment combination of everolimus and metformin, as the patient discontinued study participation before the per-protocol start of metformin on day 8 of the study

\begin{tabular}{|c|c|c|c|c|c|c|c|}
\hline $\begin{array}{l}\mathrm{Pt} \\
\#\end{array}$ & $\begin{array}{l}\text { Everolimus } \\
\text { dose (mg) }\end{array}$ & $\begin{array}{l}\text { Metformin } \\
\text { dose (mg) }\end{array}$ & DLT (grade) & SAE (grade) & $\begin{array}{l}\text { Days on } \\
\text { study }\end{array}$ & $\begin{array}{l}\text { Reason for study } \\
\text { termination }\end{array}$ & $\begin{array}{l}\text { Overall survival } \\
\text { (days after start of } \\
\text { study) }\end{array}$ \\
\hline 1 & 10 & 500 , bid & - & - & 69 & $\mathrm{PD}$ & 114 \\
\hline 2 & 10 & 500, bid & $\begin{array}{l}\text { Thrombocytopenia } \\
\text { (3)* }\end{array}$ & - & 52 & Toxicity & 158 \\
\hline 3 & 10 & 500 , bid & $\operatorname{Rash}(3)^{* *}$ & - & 78 & Toxicity & 229 \\
\hline 4 & 10 & 500 , bid & $\begin{array}{l}\text { Thrombocytopenia } \\
\text { (3) }\end{array}$ & Sepsis (4) & 14 & Toxicity & 82 \\
\hline 5 & 10 & 500, bid & - & - & 48 & PD & 145 \\
\hline 6 & 5 & 500, bid & - & Collapse (3) & 10 & Toxicity & 83 \\
\hline 7 & 5 & 500, bid & - & $\begin{array}{l}\text { Bile duct stenosis (3), obstruction } \\
\text { esophagus (3) }\end{array}$ & 71 & PD & 184 \\
\hline 8 & 5 & 500, bid & - & - & 29 & Toxicity & 53 \\
\hline
\end{tabular}

Abbreviations: $D L T$ dose-limiting toxicity, $S A E$ serious adverse event, $P D$ progressive disease

*The everolimus dose of patient \#2 was de-escalated to $5 \mathrm{mg}$ after the DLT

**The metformin dose of patient \#3 was de-escalated to $500 \mathrm{mg}$ qd after the DLT 
Table 4 Possible, probable or definitively treatment-related adverse events

\begin{tabular}{|c|c|c|c|c|}
\hline \multirow{3}{*}{$\begin{array}{l}\text { Dose level: } \\
\text { Number of patients: } \\
\text { CTCAE grade: }\end{array}$} & \multicolumn{2}{|c|}{ Dose level 1} & \multicolumn{2}{|c|}{ Dose level -1 } \\
\hline & \multicolumn{2}{|c|}{$n=6$} & \multicolumn{2}{|c|}{$n=3(+2)$} \\
\hline & $1-2$ & $3-4$ & $1-2$ & $3-4$ \\
\hline \multicolumn{5}{|l|}{ Hematological } \\
\hline Thrombopenia & 3 & $2 *$ & & \\
\hline Anemia & 2 & & & \\
\hline Leucopenia & 2 & & & \\
\hline Neutropenia & 1 & & & \\
\hline \multicolumn{5}{|l|}{ Clinical chemistry } \\
\hline Hyperbilirubinemia & & & & 1 \\
\hline Renal insufficiency & 1 & & & \\
\hline \multicolumn{5}{|l|}{ Clinical } \\
\hline Skin rash & 1 & $1 *$ & & \\
\hline Melena 1002 & & 1 & & \\
\hline Sepsis & & 1 & & \\
\hline Epistaxis & 3 & & & \\
\hline Fatigue & 3 & & & \\
\hline Anorexia & 2 & & & \\
\hline Cough & 2 & & & \\
\hline Dry skin & 1 & & (1) & \\
\hline Mucositis 1001 & 2 & & & \\
\hline Nausea & 1 & & & \\
\hline Stomatitis & 1 & & (1) & \\
\hline Blood in stool 1002 & 1 & & & \\
\hline Diarrhea 1002 & 1 & & & \\
\hline Erythema & 1 & & & \\
\hline Gingival bleeding & 1 & & & \\
\hline Hand-foot syndrome & 1 & & & \\
\hline Paronychia & 1 & & & \\
\hline Pruritus & 1 & & & \\
\hline Swollen tongue & & & (1) & \\
\hline Weight loss & 1 & & & \\
\hline
\end{tabular}

Numbers represent number of patients. Numbers between brackets at the -1 dose level represent patients that experienced adverse events after intrapatient dose de-escalation from dose level 1 to dose level -1

Abbreviations: CTCAE Common Terminology Criteria for Adverse Events version 3.0

*Indicates that the adverse event was also a DLT

adverse events, one patient with a grade 4 sepsis, two patients with grade 3 thrombocytopenia, one patient with a grade 3 rash, one patient with a grade 3 melena and one patient with a grade 3 hyperbilirubinemia were observed. The most frequently reported clinical toxicities of any grade included epistaxis, fatigue (both 33\%), anorexia, coughing, dry skin, mucositis, skin rash and stomatitis (all 22\%). The combination of everolimus and metformin did not induce significant changes in hematological or clinical chemistry parameters.
Interestingly, glucose and insulin levels increased instead of decreased during study treatment (Supplementary Table 1).

Pharmacokinetics Concentration-time curves of everolimus and metformin, both as single agents and in combination, were obtained from seven patients and are shown in Fig. 1. The observed pharmacokinetic parameters for patients with complete concentration time-curves are shown in Table 5 and Supplementary Table 2. An increased everolimus clearance was observed when it was administered in combination with metformin than as single agent (clearance: $0.018 \mathrm{l} / \mathrm{h}$ vs. $0.0097 \mathrm{l} / \mathrm{h} ; P=0.0018$ ), but this did not affect everolimus exposure (area under the curve, AUC). No difference in clearance was detected between metformin administration as single agent or in combination with everolimus $(61.1 \mathrm{l} / \mathrm{h}$ vs. $59.9 \mathrm{l} / \mathrm{h}$, $P=0.86)$. Nevertheless, the $\mathrm{t}_{1 / 2}$ and elimination rate constant $\left(\lambda_{z}\right)$ of metformin were increased when co-administered with everolimus as compared with single-agent administration $\left(\mathrm{t}_{1 / 2}\right.$ : $7.95 \mathrm{~h}$ vs. $4.16 \mathrm{~h} ; P=0.017$ and $\lambda_{\mathrm{z}}: 0.17 \mathrm{~h}^{-1}$ vs. $0.09 \mathrm{~h}^{-1}$; $P=0.005)$. The metformin AUC was comparable between
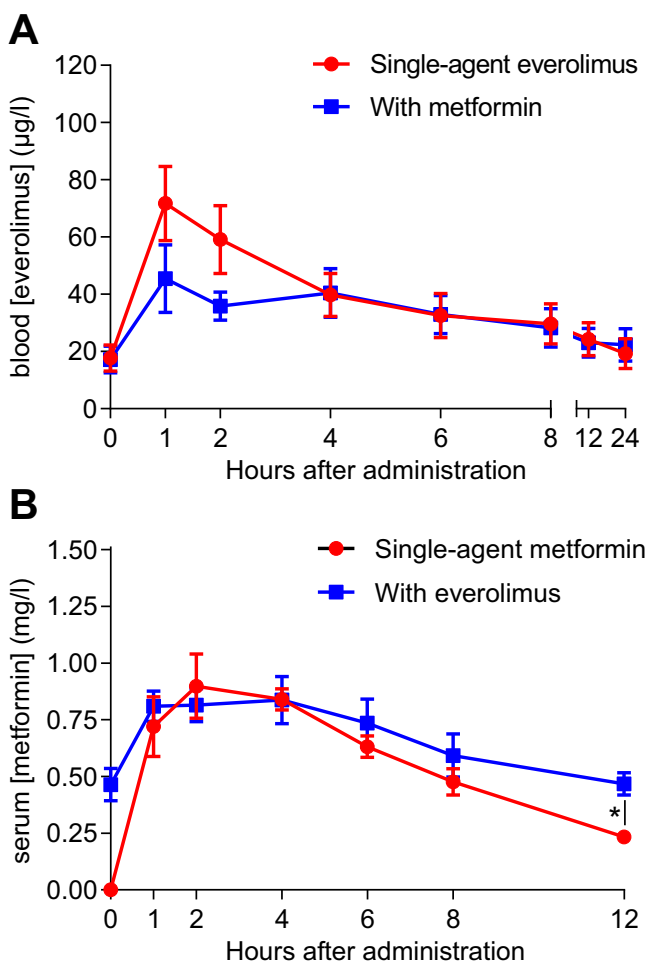

Fig. 1 Concentration curves of everolimus and metformin when administered as single-agent and in combination. a Mean \pm SEM of the blood everolimus concentration-time curves in $\mu \mathrm{g} / 1$ of 5 evaluable patients who received $10 \mathrm{mg}$ everolimus qd. b Mean \pm SEM of the serum metformin concentration-time curves in $\mathrm{mg} / \mathrm{l}$ of 7 evaluable patients who received $500 \mathrm{mg}$ metformin bid. Everolimus and metformin levels were determined in whole blood and in serum, respectively, by high-performance liquid chromatography with tandem mass spectrometry (HPLC-MS/MS). The maximum concentration levels in the figure do not necessary correspond with the $\mathrm{C}_{\max }$ as described in Table 5, because not all patients had their $\mathrm{C}_{\max }$ at the same time point 
Table 5 Pharmacokinetic parameters of everolimus and metformin when administered as single-agent and in combination. Data are mean (SD)

\begin{tabular}{|c|c|c|c|c|c|c|c|}
\hline \multirow[t]{2}{*}{ Parameter } & \multirow[t]{2}{*}{ Unit } & \multicolumn{3}{|c|}{ Everolimus $10 \mathrm{mg}$ qd $(n=5)$} & \multicolumn{3}{|c|}{ Metformin $500 \mathrm{mg}$ bid $(n=5)$} \\
\hline & & Single-agent & In combination & $P$ value & Single-agent & In combination & $P$ value \\
\hline $\mathrm{C}_{\max }$ & $\mu \mathrm{g} / 1$ & $73.1(28.5)$ & $53.3(20.7)$ & 0.18 & $912(227)$ & $1027(261)$ & 0.31 \\
\hline $\mathrm{T}_{1 / 2}$ & $\mathrm{~h}$ & $23.1(7.1)^{*}$ & $23.2(5.5)^{*}$ & 0.95 & $4.16(0.44)$ & $7.95(2.03)$ & 0.017 \\
\hline$\lambda_{\mathrm{z}}$ & $\mathrm{h}^{-1}$ & $0.028(0.006)$ & $0.029(0.006)$ & 0.77 & $0.17(0.02)$ & $0.09(0.02)$ & 0.005 \\
\hline AUC & $\mathrm{mg} / 1 * \mathrm{~h}$ & $0.713(0.35)$ & $0.639(0.30)$ & 0.50 & $8.32(1.18)$ & $8.12(1.87)$ & 0.78 \\
\hline $\mathrm{CL} / \mathrm{F}$ & $\mathrm{mg} /(\mathrm{mg} / \mathrm{l}) / \mathrm{h}$ & $0.0097(0.004)^{*}$ & $0.018(0.006)^{*}$ & 0.0018 & $61.1(9.0)$ & $59.9(14.7)$ & 0.86 \\
\hline $\mathrm{V}_{\mathrm{z}} / \mathrm{F}$ & $\mathrm{mg} /(\mathrm{mg} / \mathrm{L})$ & $0.30(0.004)^{*}$ & $0.34(0.15)^{*}$ & 0.13 & $366(60)$ & $461(15)$ & 0.16 \\
\hline
\end{tabular}

Abbreviations: $C_{\max }$ maximal concentration, $t_{1 / 2}$, elimination half-life, $\lambda_{z}$, elimination rate constant, $A U C$ area under the curve, $C L$ clearance, $F$ systemic availability of the administered dose, $V_{z}$ apparent volume of distribution during terminal phase

$* \mathrm{~T}_{1 / 2}, \mathrm{CL}$ and $\mathrm{V}_{\mathrm{z}}$ are pharmacokinetic parameters that are independent of dose and were calculated for all 7 patients with everolimus concentration-time curves. The $24 \mathrm{~h}$ time point of patient $\# 3$ was calculated using extrapolation of the $6 \mathrm{~h}, 8 \mathrm{~h}$ and $12 \mathrm{~h}$ time points on a logarithmic scale. $P$ values were calculated using paired Student's $t$-test. Pharmacokinetic parameters for 2 patients who received $5 \mathrm{mg}$ everolimus qd and $500 \mathrm{mg}$ metformin bid are shown in Supplementary Table 2

single-agent administration and co-administration with everolimus. There was no association between the extent of pharmacokinetic interaction between everolimus and metformin and the occurrence of toxicity in the individual patients. Three patients (\#5, \#8 and \#9) had a higher exposure to metformin when administered in combination with everolimus than as single agent due to slower drug elimination (Supplementary Figs. 1 and 2), but patients \#5 and \#8 experienced only minor toxicity and discontinued study treatment due to progressive disease. Although patients \#8 and \#9 had incomplete concentration-time curves for metformin, they had an evidently increased metformin exposure when administered in combination with everolimus. However, due to the incompleteness of their data, they could not be included in the quantitative pharmacokinetic analyses shown in Table 5.

Tumor responses After nine weeks of treatment, three patients were still on study and all had stable disease, with tumor responses of $-14 \%,+3 \%$ and $-5 \%$ of the volume of all target lesions. The three patients that received nine weeks of treatment had a longer survival than the five patients who had to discontinue study treatment prematurely due to toxicity (median overall survival: 184 days vs. 82 days; $P=0.0482$, Table 3). Of the three patients that received nine weeks of treatment, two eventually discontinued study treatment due to progressive disease and one because of toxicity reasons (Table 3). The nine-week time point for this survival analysis was prespecified because patients were to receive a CT scan to evaluate tumor responses at this time point.

\section{Discussion}

This study explored the safety and pharmacokinetics of the combination of everolimus and metformin in patients with advanced solid malignancies. We found that a combination regimen of everolimus and metformin is poorly tolerated in these patients. Therefore, we were unable to determine the MTD for this combination treatment.

Recently, a retrospective study of 31 patients with pancreatic neuroendocrine tumors (PNETs) was published [30]. This study showed improved clinical outcomes to treatment with everolimus and octreotide in patients that were also treated with metformin for diabetes as compared with patients that were treated with insulin or as compared with nondiabetic patients. In contrast to our study, Pusceddu et al. [30] made no mention of intolerable toxicity. By speculation, possible explanations for this apparent difference come to mind. First, diabetic PNET patients that were already being treated with metformin may better tolerate everolimus than cancer patients that are treated with metformin and everolimus for the first time because the former group may have had more time to habituate to metformin. Second, metformin was administered $500 \mathrm{mg}$ bid upfront in our study, whereas the patients described by Pusceddu et al. received metformin after a titration period, starting at $500 \mathrm{mg}$ qd in the first week [30]. The latter approach mimics metformin treatment schedules in T2DM and decreases the initial side effects of metformin, especially those of gastro-intestinal nature [31, 32]. What argues against this possible explanation for metformin toxicity is that only two patients of the present study experienced gastro-intestinal side-effects and all gastro-intestinal side-effects were grade 1-2, except one case of grade 3 melaena. Third, octreotide might ameliorate the toxic effects of the combination regimen of everolimus and metformin through mechanisms that are still unknown. Fourth, a retrospective study design such as that of Pusceddu et al. might lead to unintentional under-ascertainment of toxicity when sideeffects lead to discontinuation of treatment, which prevents the inclusion of these patients in a retrospective analysis. 
In a phase I clinical trial, Khawaja et al. investigated the combination of metformin and another mTOR inhibitor, the intravenously administered temsirolimus [14]. The authors concluded that this combination was well tolerated with only two DLTs observed among 21 patients and an MTD/ recommended dose of $25 \mathrm{mg}$ temsirolimus weekly and $1000 \mathrm{mg}$ metformin bid. In contrast, MacKenzie et al. observed severe toxicity in a similar phase I clinical trial in patients with advanced cancers that were also treated with metformin and temsirolimus, reporting an MTD of $20 \mathrm{mg}$ temsirolimus weekly and $500 \mathrm{mg}$ metformin qd [33]. The main difference between the two study designs was that the former utilized a titration period for metformin to limit its toxicity, whereas the latter did not.

On one hand, altered pharmacokinetics of everolimus were observed when everolimus was administered in combination with metformin as compared with everolimus single-agent administration. While the maximal everolimus concentration was lower in combination than as single-agent, this was statistically not significant but still might suggest that metformin affects everolimus absorption. Furthermore, everolimus clearance was significantly higher in combination with metformin than as single-agent, while the elimination half-life was unchanged, possibly due to a moderate, but unsignificant, increase in the volume of distribution.

On the other hand, altered metformin pharmacokinetics were observed when metformin was administered in combination with everolimus as compared with metformin single-agent administration, i.e. a lower elimination halflife and elimination rate constant. However, the significantly slower metformin elimination was not accompanied by a significantly slower clearance. This might be explained by a moderate, but unsignificant, increase in the volume of distribution. The slower metformin elimination did not translate to higher AUCs in combination with everolimus versus single-agent administration, which suggest that the observed toxicity of the study treatment cannot be explained by higher metformin AUCs in combination with everolimus versus single-agent administration. A limitation of our pharmacokinetic analysis is that two patients who had an evidently increased exposure to metformin due to slower drug elimination had incomplete timeconcentration curves and could thus not be included in our pharmacokinetic analysis. This may explain why the quantitative pharmacokinetic analysis did not show a higher metformin AUC when administered in combination with everolimus relative to single-agent administration. Alternatively, our results may suggest that pharmacodynamic rather than pharmacokinetic interactions between everolimus and metformin explain the high toxicity of this drug combination. To the best of our knowledge, there is no data on pharmaco-interactions between everolimus and metformin at the clinical or molecular level yet.
The combination of everolimus and metformin was tolerated for at least nine weeks in three patients and they all had stable disease. Patients treated with everolimus and metformin for at least nine weeks had a prolonged survival compared with those who had to discontinue study treatment prematurely due to toxicity, but these analyses were conducted in very small groups and should be carefully considered as merely preliminary evidence of anti-tumor efficacy of the combination of an mTOR inhibitor and a biguanide. Another study, investigating a combination of metformin and the MTOR inhibitor temsirolimus, also observed modestly promising antitumor efficacy in a cohort with heavily pretreated patients with advanced cancer [14].

In conclusion, results from a prospective, open-label, single-center phase I study show that the combination of everolimus and metformin is poorly tolerated in patients with advanced cancer. This may be due to pharmaco-interactions between the two drugs, because everolimus delayed and inhibited the elimination of metformin. Our findings have implications for daily practice, especially for diabetic patients using metformin that also have a cancer being treated with everolimus. In addition, our data may be important for the interpretation and design of ongoing and future clinical trials that study the combination of everolimus and metformin (see ClinicalTrials.gov entries NCT01627067, NCT01797523 and NCT02294006). Although our analyses of tumor responses and overall survival are based on very small groups and should be interpreted with the greatest caution, they could suggest that combining an mTOR inhibitor and a biguanide has anti-cancer activity in patients with advanced cancer. Therefore, alternative combination regimens [14] could be investigated in future studies with drugs other than metformin and/or everolimus.

Acknowledgements This study was funded by the Academic Medical Center. R.J.M. was supported by an AMC PhD Scholarship.

Author contributions R.A.M, D.R. and J.W.W. designed research. R.J.M., M.J.W., H.-J.K. and J.W.W. performed research. R.J.M., R.A.M. and J.W.W. analyzed data. R.J.M., T.v.d.V. and J.W.W. wrote the manuscript. All authors read and approved the manuscript and its conclusions.

\section{Compliance with ethical standards}

Conflict of interest R.J.M. declares that he has no conflict of interest. T.v.d.V. declares that he has no conflict of interest. M.J.W. declares that she has no conflict of interest. R.A.M. declares that he has no conflict of interest. H-J.K. declares that he has no conflict of interest. D.J.R. declares that he has no conflict of interest. J.W.W. declares that she has no conflict of interest.

Ethical approval All procedures performed in studies involving human participants were in accordance with the ethical standards of the institutional and/or national research committee and with the 1964 Helsinki declaration and its later amendments or comparable ethical 
standards. This article does not contain any studies with animals performed by any of the authors. The study protocol was approved by the Medical Ethics Committee of the Academic Medical Center (reference number NL_37906.018.12).

Informed consent Informed consent was obtained from all individual participants included in the study.

Open Access This article is distributed under the terms of the Creative Commons Attribution 4.0 International License (http:// creativecommons.org/licenses/by/4.0/), which permits unrestricted use, distribution, and reproduction in any medium, provided you give appropriate credit to the original author(s) and the source, provide a link to the Creative Commons license, and indicate if changes were made.

\section{References}

1. Zoncu R, Efeyan A, Sabatini DM (2011) mTOR: from growth signal integration to cancer, diabetes and ageing. Nat Rev Mol Cell Biol 12(1):21-35. doi:10.1038/nrm3025

2. Yao JC, Fazio N, Singh S, Buzzoni R, Carnaghi C, Wolin E, Tomasek J, Raderer M, Lahner H, Voi M, Pacaud LB, Rouyrre N, Sachs C, Valle JW, Delle Fave G, Van Cutsem E, Tesselaar M, Shimada Y, Oh DY, Strosberg J, Kulke MH, Pavel ME, Rad001 in Advanced Neuroendocrine Tumours FTSG (2016) Everolimus for the treatment of advanced, non-functional neuroendocrine tumours of the lung or gastrointestinal tract (RADIANT-4): a randomised, placebo-controlled, phase 3 study. Lancet 387(10022):968-977. doi:10.1016/S0140-6736(15)00817-X

3. Demetri GD, Chawla SP, Ray-Coquard I, Le Cesne A, Staddon AP, Milhem MM, Penel N, Riedel RF, Bui-Nguyen B, Cranmer LD, Reichardt P, Bompas E, Alcindor T, Rushing D, Song Y, Lee RM, Ebbinghaus S, Eid JE, Loewy JW, Haluska FG, Dodion PF, Blay JY (2013) Results of an international randomized phase III trial of the mammalian target of rapamycin inhibitor ridaforolimus versus placebo to control metastatic sarcomas in patients after benefit from prior chemotherapy. J Clin Oncol 31(19):2485-2492. doi:10.1200/ JCO.2012.45.5766

4. Franz DN, Belousova E, Sparagana S, Bebin EM, Frost M, Kuperman R, Witt O, Kohrman MH, Flamini JR, Wu JY, Curatolo P, de Vries PJ, Whittemore VH, Thiele EA, Ford JP, Shah G, Cauwel H, Lebwohl D, Sahmoud T, Jozwiak S (2013) Efficacy and safety of everolimus for subependymal giant cell astrocytomas associated with tuberous sclerosis complex (EXIST-1): a multicentre, randomised, placebo-controlled phase 3 trial. Lancet 381(9861):125-132. doi:10.1016/S0140-6736(12)61134-9

5. Hess G, Herbrecht R, Romaguera J, Verhoef G, Crump M, Gisselbrecht C, Laurell A, Offner F, Strahs A, Berkenblit A, Hanushevsky O, Clancy J, Hewes B, Moore L, Coiffier B (2009) Phase III study to evaluate temsirolimus compared with investigator's choice therapy for the treatment of relapsed or refractory mantle cell lymphoma. J Clin Oncol 27(23):3822-3829. doi: 10.1200/JCO.2008.20.7977

6. Motzer RJ, Escudier B, Oudard S, Hutson TE, Porta C, Bracarda S, Grunwald V, Thompson JA, Figlin RA, Hollaender N, Urbanowitz G, Berg WJ, Kay A, Lebwohl D, Ravaud A, Group R-S (2008) Efficacy of everolimus in advanced renal cell carcinoma: a doubleblind, randomised, placebo-controlled phase III trial. Lancet 372(9637):449-456. doi:10.1016/S0140-6736(08)61039-9

7. Rozengurt E (2014) Mechanistic target of rapamycin (mTOR): a point of convergence in the action of insulin/IGF-1 and G proteincoupled receptor agonists in pancreatic cancer cells. Front Physiol 5:357. doi:10.3389/fphys.2014.00357
8. Vivanco I, Sawyers CL (2002) The phosphatidylinositol 3-kinase AKT pathway in human cancer. Nat Rev Cancer 2(7):489-501. doi: 10.1038/nrc839

9. O'Reilly KE, Rojo F, She QB, Solit D, Mills GB, Smith D, Lane H, Hofmann F, Hicklin DJ, Ludwig DL, Baselga J, Rosen N (2006) mTOR inhibition induces upstream receptor tyrosine kinase signaling and activates Akt. Cancer Res 66(3):1500-1508. doi:10.1158/ 0008-5472.CAN-05-2925

10. Guertin DA, Sabatini DM (2009) The pharmacology of mTOR inhibition. Sci Signal 2(67):pe24. doi:10.1126/scisignal.267pe24

11. Wang Y, Wei J, Li L, Fan C, Sun Y (2014) Combined use of metformin and Everolimus is synergistic in the treatment of breast cancer cells. Oncol Res 22(4):193-201. doi:10.3727/ $096504015 \times 14348950540999$

12. Liu H, Scholz C, Zang C, Schefe JH, Habbel P, Regierer AC, Schulz CO, Possinger K, Eucker J (2012) Metformin and the mTOR inhibitor everolimus (RAD001) sensitize breast cancer cells to the cytotoxic effect of chemotherapeutic drugs in vitro. Anticancer Res 32(5):1627-1637

13. Zakikhani M, Blouin MJ, Piura E, Pollak MN (2010) Metformin and rapamycin have distinct effects on the AKT pathway and proliferation in breast cancer cells. Breast Cancer Res Treat 123(1): 271-279. doi:10.1007/s10549-010-0763-9

14. Khawaja MR, Nick AM, Madhusudanannair V, Fu S, Hong D, McQuinn LM, Ng CS, Piha-Paul SA, Janku F, Subbiah V, Tsimberidou A, Karp D, Meric-Bernstam F, Lu KH, Naing A (2016) Phase I dose escalation study of temsirolimus in combination with metformin in patients with advanced/refractory cancers. Cancer Chemother Pharmacol 77(5):973-977. doi:10.1007/ s00280-016-3009-7

15. Mackay HJ, Eisenhauer EA, Kamel-Reid S, Tsao M, Clarke B, Karakasis K, Werner HM, Trovik J, Akslen LA, Salvesen HB, Tu D, Oza AM (2014) Molecular determinants of outcome with mammalian target of rapamycin inhibition in endometrial cancer. Cancer 120(4):603-610. doi:10.1002/cncr.28414

16. Slomovitz BM, Jiang Y, Yates MS, Soliman PT, Johnston T, Nowakowski M, Levenback C, Zhang Q, Ring K, Munsell MF, Gershenson DM, Lu KH, Coleman RL (2015) Phase II study of everolimus and letrozole in patients with recurrent endometrial carcinoma. J Clin Oncol 33(8):930-936. doi:10.1200/JCO.2014.58.3401

17. Kordes S, Pollak MN, Zwinderman AH, Mathot RA, Weterman MJ, Beeker A, Punt CJ, Richel DJ, Wilmink JW (2015) Metformin in patients with advanced pancreatic cancer: a doubleblind, randomised, placebo-controlled phase 2 trial. Lancet Oncol 16(7):839-847. doi:10.1016/S1470-2045(15)00027-3

18. Zhang ZJ, Bi Y, Li S, Zhang Q, Zhao G, Guo Y, Song Q (2014) Reduced risk of lung cancer with metformin therapy in diabetic patients: a systematic review and meta-analysis. Am J Epidemiol 180(1):11-14. doi:10.1093/aje/kwu124

19. Bodmer M, Meier C, Krahenbuhl S, Jick SS, Meier CR (2010) Long-term metformin use is associated with decreased risk of breast cancer. Diabetes Care 33(6):1304-1308. doi:10.2337/dc09-1791

20. Evans JM, Donnelly LA, Emslie-Smith AM, Alessi DR, Morris AD (2005) Metformin and reduced risk of cancer in diabetic patients. BMJ 330(7503):1304-1305. doi:10.1136/bmj.38415.708634.F7

21. Wang Z, Lai ST, Xie L, Zhao JD, Ma NY, Zhu J, Ren ZG, Jiang GL (2014) Metformin is associated with reduced risk of pancreatic cancer in patients with type 2 diabetes mellitus: a systematic review and meta-analysis. Diabetes Res Clin Pract 106(1):19-26. doi:10. 1016/j.diabres.2014.04.007

22. Sadeghi N, Abbruzzese JL, Yeung SC, Hassan M, Li D (2012) Metformin use is associated with better survival of diabetic patients with pancreatic cancer. Clin Cancer Res 18(10):2905-2912. doi:10. 1158/1078-0432.CCR-11-2994

23. Lin HC, Kachingwe BH, Lin HL, Cheng HW, Uang YS, Wang LH (2014) Effects of metformin dose on cancer risk reduction in 
patients with type 2 diabetes mellitus: a 6-year follow-up study. Pharmacotherapy 34(1):36-45. doi:10.1002/phar.1334

24. Yin M, Zhou J, Gorak EJ, Quddus F (2013) Metformin is associated with survival benefit in cancer patients with concurrent type 2 diabetes: a systematic review and meta-analysis. Oncologist 18(12): 1248-1255. doi:10.1634/theoncologist.2013-0111

25. Eisenhauer EA, Therasse P, Bogaerts J, Schwartz LH, Sargent D, Ford R, Dancey J, Arbuck S, Gwyther S, Mooney M, Rubinstein L, Shankar L, Dodd L, Kaplan R, Lacombe D, Verweij J (2009) New response evaluation criteria in solid tumours: revised RECIST guideline (version 1.1). Eur J Cancer 45(2):228-247. doi:10.1016/ j.ejca.2008.10.026

26. Graham GG, Punt J, Arora M, Day RO, Doogue MP, Duong JK, Furlong TJ, Greenfield JR, Greenup LC, Kirkpatrick CM, Ray JE, Timmins P, Williams KM (2011) Clinical pharmacokinetics of metformin. Clin Pharmacokinet 50(2):81-98. doi:10.2165/11534750-000000000-00000

27. Kirchner GI, Meier-Wiedenbach I, Manns MP (2004) Clinical pharmacokinetics of everolimus. Clin Pharmacokinet 43(2):83-95. doi: 10.2165/00003088-200443020-00002

28. Winter ME (2010) Basic clinical pharmacokinetics, 5th edn. Wolters Kluwer/Lippincott Williams \& Wilkins Health, Philadelphia
29. Zhang Y, Huo M, Zhou J, Xie S (2010) PKSolver: an add-in program for pharmacokinetic and pharmacodynamic data analysis in Microsoft excel. Computer Meth Prog Biomed 99(3):306-314. doi: 10.1016/j.cmpb.2010.01.007

30. Pusceddu S, Buzzoni R, Vernieri C, Concas L, Marceglia S, Giacomelli L, Milione M, Leuzzi L, Femia D, Formisano B, Mazzaferro V, de Braud F (2016) Metformin with everolimus and octreotide in pancreatic neuroendocrine tumor patients with diabetes. Future Oncol 12(10):1251-1260. doi:10.2217/fon-2015-0077

31. Nathan DM, Buse JB, Davidson MB, Heine RJ, Holman RR, Sherwin R, Zinman B, Professional Practice Committee ADA, European Association for the Study of D (2006) Management of hyperglycaemia in type 2 diabetes: a consensus algorithm for the initiation and adjustment of therapy. A consensus statement from the American Diabetes Association and the European Association for the Study of diabetes. Diabetologia 49(8):1711-1721. doi:10. 1007/s00125-006-0316-2

32. McCreight LJ, Bailey CJ, Pearson ER (2016) Metformin and the gastrointestinal tract. Diabetologia 59(3):426-435. doi:10.1007/ s00125-015-3844-9

33. MacKenzie MJ, Ernst S, Johnson C, Winquist E (2012) A phase I study of temsirolimus and metformin in advanced solid tumours. Invest New Drugs 30(2):647-652. doi:10.1007/s10637-010-9570-8 